ORIGINAL ARTICLE

\title{
Women's accounts of consenting to surgery: is consent a quality problem?
}

\author{
M Habiba, C Jackson, A Akkad, S Kenyon, M Dixon-Woods
}

See editorial commentary, p 414

Qual Saf Health Care 2004;13:422-427. doi: 10.1136/qshc.2004.010652

Background: Consent has been placed at the centre of doctor-patient relationships. Attempts to improve the consent process in medicine have drawn on bioethical and legal traditions. Current approaches to consent emphasise the provision of information and have, in the UK, resulted in a single standardised format and process for both elective and emergency situations. Investigation of patients' perceptions and priorities are important in understanding the quality of the consent process.

See end of article for authors' affiliations

.....................

Correspondence to: DrM Dixon-Woods, Reproductive Sciences Section, University of Leicester, 22-28 Princess Road West, Leicester LE1 6TP, UK; md11@le.ac.uk

Accepted for publication 23 July 2004
Methods: In this qualitative study, semi-structured interviews were conducted with 25 women. Eleven had elective and 14 had emergency operations in obstetrics and gynaecology. All interviews were recorded and transcribed verbatim. Data analysis was based on the constant comparative method.

Results: Participants' perceptions of surgery strongly influenced the meanings they gave to consent. Some, particularly those undergoing elective operations, wanted surgery. Others were uncertain of their desire for surgery or felt that it was imposed on them. Consenting was interpreted as a ritualistic legal procedure. There was an overwhelming tendency to view consent as not primarily serving patients' needs, although some advantages of the consent process were identified. Accounts made no reference to ethics.

Conclusion: Countering paternalism will remain difficult to achieve if issues surrounding consent continue to be debated between professionals without due effort to reflect patients' own views and values and to appreciate the circumstances under which consent is sought.
$\mathrm{D}$ espite its relatively short history, ${ }^{1}$ consent has evolved into an apparently essential component of doctorpatient interaction. It is increasingly seen as the means by which ethical ideals of respecting individuals, their rights and autonomy can best be realised. ${ }^{2}$ The role of consent at the interface between patients and healthcare providers has been endorsed through recent policy and professional statements that have emphasised its place as fundamental to good practice. $^{3-5}$

Current conceptualisations of consent rest on assumptions of patients as autonomous moral agents, capable of making rational choices when provided with full and relevant information, and emphasise the need for patient involvement and partnership. ${ }^{3}$ The need for shared decision making is driven, at least in part, by pressures from the bioethical and legal field to move away from paternalism and to respect patient autonomy. ${ }^{67}$ Consent, operationalised through the act of signing a consent form, is promoted as a means by which these ideals may be achieved. ${ }^{4}$

Clearly, if consent is to enjoy this important status in signalling not only acquiescence to medical intervention but also in demonstrating the outcomes of joint decision making processes, then understanding people's experiences and views on consent is crucial. However, much of the attention in investigating consent has focused on disclosure, including the provision of sufficient information to achieve "informed" consent. $^{8-11}$ Case law has further highlighted the compulsory nature of information provision, ${ }^{12-14}$ and many published studies characterise quality of consent in terms such as information disclosure or fact retention. However, disclosure is likely to be only one element of the consent process, and there is a need to understand the process more broadly. Recent critiques have identified the tendency of bioethics to emphasise abstract principles at the expense of empirical examination of real life cases that examine structures of power in medical interactions. ${ }^{15}$ The need for bioethics to engage with the ways in which people experience, interpret, and understand decision making within the social context of healthcare settings and professional-patient relationships has been emphasised. ${ }^{16}$

Given the central role of consent and recent public and media interest, it remains surprising how little effort has been directed towards exploring patients' experiences of the process. Little is known about whether the process addresses their needs and the extent to which it fulfils the objectives of signalling partnership and countering paternalism. Our study examined narratives about experiences of giving consent from women who had undergone surgical procedures. Our aim was to enhance our understanding of the process of giving consent as viewed by the women in general, not as it relates to a specific surgical procedure. We aimed to explore the narratives of those who had undergone surgery (both elective and emergency). We included different types of surgery because it is important to understand the experiences of candidates for surgery under different circumstances of urgency and stress, and consent in the National Health Service currently allows for a single standardised consent form process for adults with capacity. No published research has investigated the extent to which this uniform process might address very diverse experiences and needs, including those that arise in pregnancy and childbirth. We did not aim to compare directly accounts of elective and emergency patients, but allowed any differences or similarities to emerge through analysis.

\section{METHODS}

The study was conducted between December 2001 and November 2002 with the approval of the Leicestershire research ethics committee. It involved semi-structured interviews with women who had recently undergone surgery in obstetrics and gynaecology and who signed a consent form at a large teaching hospital in the East Midlands, UK. The project team included a panel of eight lay members who had recently undergone surgery and who represented a mix of 
experiences. This panel advised on the appropriateness of approach and construction of the prompt guide, and helped to ensure that the project was explicitly attentive to a patient perspective.

\section{Participants}

Women who had recently undergone surgery were approached for inclusion in the study. It was decided to focus on women who had undergone surgery for obstetric or gynecological conditions to allow exploration of the different circumstances under which consent is given while also avoiding making the sample too diverse. Purposive maximum variation sampling, which does not aim for statistical representativeness, was initially used to select potential participants ${ }^{17}$ in order to select those with as wide a range of characteristics as possible within the definition of the sample. Theoretical sampling, where the aim is to develop and challenge the emerging analysis, was also used. We aimed to select participants based on whether they had undergone emergency or elective surgery, and on demographic characteristics including age, socioeconomic background, and ethnicity. Emergency surgery was defined as that which ensued following an emergency hospital admission for an acute condition (including childbirth). All emergency operations were performed within 24 hours of the patient signing the consent form for the surgery.

\section{Interviews}

All participants were interviewed at home by CJ, who maintained a reflexive diary to record contextual details of the interviews and her reflections on the research process. An interview prompt guide was developed using a review of literature, discussions within the project team, and contributions from the patient panel. The guide aimed to prompt women's views and experiences of giving consent to surgery. The emphasis was on encouraging participants to articulate their views in their own terms, and the prompt guide was used flexibly in response to the directions in which participants wanted to take the interview. The prompt guide was modified (albeit only modestly) throughout the project in response to emerging themes. All interviews were tape recorded and transcribed verbatim.

\section{Analysis of data}

Data analysis was based on the constant comparative method. ${ }^{18}$ "Open" codes to describe each unit of meaning were initially generated. Through comparison across transcripts, the open codes were developed into higher order thematic categories to provide a framework for coding, assisted by QSR N5 software. ${ }^{19}$ The framework categories were continually checked and modified to ensure an adequate "fit" with the data while accounting for negative cases and the assignment of the data to the categories was independently validated. An audit trail of the development of the framework and its categories was maintained in the reflexive diary.

\section{RESULTS}

Three women who were approached refused to be interviewed. Twenty six women agreed to participate in the study, but one tape was unusable for technical reasons, leaving accounts of 25 women aged 19-70 years available for analysis. Eleven underwent elective surgery and 14 had emergency operations (table 1). A consent form for surgery has been signed in the 4 weeks before the interviews took place. Caesarean section is the most common emergency procedure in obstetrics and gynaecology that requires a consent form and was of particular interest and relevance for theoretical sampling. Six patients worked at home caring for
Table 1 Surgical procedures undergone by study participants

\begin{tabular}{|c|c|}
\hline & $\begin{array}{l}\text { No of } \\
\text { participants }\end{array}$ \\
\hline \multicolumn{2}{|l|}{ Elective procedures: } \\
\hline $\begin{array}{l}\text { Abdominal hysterectomy (removal of the uterus } \\
\text { through an abdominal incision) }\end{array}$ & 2 \\
\hline $\begin{array}{l}\text { Vaginal hysterectomy (removal of the uterus } \\
\text { through the vagina) }\end{array}$ & 1 \\
\hline $\begin{array}{l}\text { Tubal reconstruction (repair of damaged fallopian } \\
\text { tubes) }\end{array}$ & 1 \\
\hline Sacrocolpopexy for prolapse (abdominal & 1 \\
\hline $\begin{array}{l}\text { Endometrial balloon ablation (removing the } \\
\text { uterine lining using a thermal balloon) }\end{array}$ & 1 \\
\hline $\begin{array}{l}\text { Hysteroscopy and endometrial biopsy (telescopic } \\
\text { examination of the uterus) }\end{array}$ & 1 \\
\hline $\begin{array}{l}\text { Dilatation and curettage (scraping of the } \\
\text { uterine lining) }\end{array}$ & 1 \\
\hline Caesarean section & 3 \\
\hline \multicolumn{2}{|l|}{ Emergency procedures: } \\
\hline $\begin{array}{l}\text { Salpingectomy and/or oophorectomy (removal } \\
\text { of fallopian tube) }\end{array}$ & 4 \\
\hline $\begin{array}{l}\text { Abdominal hysterectomy (removal of } \\
\text { the uterus through an abdominal incision) }\end{array}$ & 1 \\
\hline Caesarean section & 6 \\
\hline $\begin{array}{l}\text { Caesarean section, hysterectomy and repair } \\
\text { of bladder injury }\end{array}$ & 1 \\
\hline Manual removal of placenta & 2 \\
\hline
\end{tabular}

their families, 16 were employed, two were unemployed, and one was a student. Four patients were from ethnic minority groups.

Participants mostly offered detailed and lengthy accounts of their experiences of surgery, although a few had limited recollection. However, it is important that these accounts are not treated as allowing direct access to some "reality" of what happened; they are instead narratives that allowed women to describe their experiences from their own perspective.

\section{Meanings of surgery}

Our analysis identified four distinctive orientations towards surgery in the participants' accounts. The accounts of two groups suggested that they welcomed surgery; the third accepted some sort of intervention but were uncertain about the need for surgery or particular forms of surgical intervention; and the fourth group was either deeply ambivalent about surgery or hostile towards it.

\section{Surgery as fulfilment of want or desire}

All 10 participants in this group underwent planned procedures. Surgery was seen as a solution to often long standing and distressing health problems. Participants had frequently been on lengthy waiting lists and some had struggled to gain the agreement of doctors to surgery. These participants were likely to see consent as the doctor authorising or acceding to the patient's request for surgery.

"I suppose I just couldn't wait for it to happen. Um, I had waited a long, long time, I thought there is nothing that is going to stop me now. That's how I felt. I was thrilled." (Participant 13, planned)

\section{Surgery as rescue}

For the six participants (five emergency and one planned) in this group, surgery was experienced as salvation from an acutely painful or distressing situation.

"I just didn't care. It was just the pain that I was in. I just didn't care at all. I just wanted the pain to go away and if it meant surgery 
then I was quite happy to sign the consent form." (Participant 11, emergency)

Three participants in this group reported consenting as their positive approval of a decision made by doctors.

"... because they tell me before, you can't get the baby out normal now, we have to go to, to theatre ... and that I agree, I agree myself, yeah." (Participant 21, emergency)

The other three participants were less positive but did feel that they had given an endorsement of the decision to operate and did not feel that surgery had been imposed on them.

\section{Surgery as imposed rescue}

The six participants (all emergency) in this group recognised that they needed help but, in contrast with the "rescue" group, felt the surgical solution to their problem was imposed upon them and that they had had no say in the process.

"I had no say in it. It was just, the doctor said we've got to get your baby out and at the time I was in so much pain, I didn't, I just thought OK get it out... [laughs], I weren't thinking about having to have the operation or what would follow, I just... my baby was in danger and I was in pain." (Participant 4, emergency)

These women were likely to represent their experience of consent as "going along with" or cooperating with doctors in a passive way:

"er, I don't know really. Well yo... just to er, just to say 'yes you can do whatever you're gonna do to me', I suppose." (Participant 12 , emergency)

\section{Surgery as imposition}

The three participants (all emergency) in this group had not anticipated surgery and did not recognise surgery as a necessary or legitimate response to their current health problem. They did not want surgery and, in contrast to the other groups, they did not acknowledge the need for intervention. These participants talked about consenting in terms of submitting to a decision made by doctors.

"I don't understand how they can take a decision like that, how I feel now ... they took it upon themselves to decide what's best for me." (Participant 17, emergency)

\section{Meanings given to the consent form}

Our analysis generated a range of meanings that participants give to the consent form-as a legal entity, as a ritual, and as an aspect of control and power in interactions between professionals and patients.

\section{The consent form as a legal entity}

Participants' accounts identified the consent form as a legal entity which functioned both as a form of contract and as a form of proof. However, participants were unsure about its status as a contract and about the obligations on either side. While eight participants recognised that they had the right to withdraw their consent even after they had signed the form, one indicated that she believed that consent could not be withdrawn, and a further five were uncertain. There was considerable uncertainty about whether doctors could proceed with the operation in the absence of a signed consent form, particularly in emergency situations.

Sixteen participants identified the consent form as a form of legal proof. Some saw this as offering important protections to themselves and their families, in the form of evidence of what they had agreed to.

"... so there isn't going to be a dispute that you haven't said, you haven't given your consent for them to do surgery on you, if they do surgery on you and you haven't consent to do it then obviously they can be obviously penalised for it". (Participant 7, planned)

A majority $(n=20)$ of participants, however, saw the consent form as also serving interests other than their own, including those of doctors, nurses, the hospital, or the health service generally.

"I think to cover themselves, isn't just, basically just to the procedure that if ... if anything did go wrong you know, you were, you were signing to say well you know, you've accepted the ... the risks that were involved in the ... in the surgery, I don't know ... that's why they ... they get you to sign it." (Participant 19, emergency)

Some participants suggested that the consent form left them "without a leg to stand on" (participant 13) because, having signed the form, they were allowing doctors to do what it specified even if that was not what they wanted. This was an important problem, particularly for patients who experienced surgery as imposition or imposed rescue.

Some procedural advantages of consent forms were also identified, particularly as they applied to safety and reaffirming patients' rights. For example, two participants suggested that consent forms functioned as a means of "tagging" the patient and the procedure for identification, to avoid the wrong procedure being performed once the patient was anaesthetised. Eight participants also referred to the consent form as a means of ensuring or confirming that they had received the necessary information about the procedure.

\section{The consent form as a ritual}

Our analysis of participants' accounts of surgery suggested that surgery is seen as a "ceremony" involving a number of rituals. Patients identified that they are required to play a very specific role in the ceremony - that of signing the form. Signing the form was commonly represented in participants' accounts as a compulsory procedural step without which doctors could not perform operations. For participants who saw surgery as fulfilment, the consent form was of little significance: it was a bureaucratic formality, the written enactment of a decision made earlier.

"I just thought it was a recognised thing that they tell you all the gumph sort of thing and then they say will you sign a consent form and you think OK I will ... I just signed it as a matter of course. You know, it was a natural thing to do." (Participant 9, planned)

Patients who saw the surgery as rescue, imposed rescue, or imposition also saw the consent form as part of a ritual, but were less likely to see this as unproblematic. Their accounts referred to uncertainty, confusion and chaos, with consent given in busy, rushed, crowded environments including hospital wards and corridors en route to the operating theatre. Participants were often unaware of who had sought their consent, and several described situations of desperation in which the consent form played only a perfunctory or sometimes unwelcome role in the drama.

"All I remember is that it being shoved under me nose and saying you've got to go down to surgery, sign and that was it." (Participant 10 , emergency)

In keeping with the ritualistic function of the consent form, only six participants, four of whom were women who underwent surgery as fulfilment, reported that they had read the consent form in full. Eleven participants, nine of whom had undergone procedures perceived as rescue, imposed rescue or imposition, reported that they did not read the form at all. Of the remaining eight, seven reported that they read it cursorily and one could not recall whether she had read it or not.

"I just scanned through it. I didn't read the whole lot because there was loads, otherwise I would have been there ages." (Participant 20, emergency)

\section{The consent form and control and power}

The theme of control was prominent in participants' accounts. Consent forms were seen as being potentially able to offer a measure of control to patients. Ten participants, five 
who experienced surgery as fulfilment and five who experienced surgery as rescue, imposed rescue, or imposition, identified a role for the consent form in limiting what surgeons could do.

"I knew that they were only going to do this, this and this and that would be the end of it." (Participant 8, planned procedure)

Ten participants (four who experienced surgery as fulfilment, two as rescue, three as imposed rescue, and one as imposition) suggested that consent forms could function as a way for patients to retain the power to specify what would happen to them. They identified the request to sign a consent form as a moment at which they might express and exercise choice.

"It's only when the consent form comes that you have got the choice to turn round and say you don't want it. To say that was the time for you to say whether you wanted to have that done or not and if you didn't then you don't sign it." (Participant 4, emergency)

However, participants' accounts of precisely how the consent form might enable them to control the process varied. It was clear that, while many participants recognised these "in principle" functions of the consent form, their experiences suggested that, in practice, consent forms functioned in very different ways, particularly in emergency situations. The meanings attached to consent forms were highly dependent on the extent to which participants felt they endorsed the proposed surgery.

Where patients knew they were agreeing to a named procedure, many felt they were doing so without any real idea of what it would mean for them. Some patients could not precisely define the limits of the surgery for which they had signed consent, even after the operation. This problem was intensified if they did not understand the terminology used, had to deal with different doctors, or found themselves in extreme states. Accounts of eight participants reflected scepticism about the value of the consent form for the patient and questioned the validity of consent given either when in extreme physical or emotional conditions, or where decisions were perceived to be made by doctors rather than patients.

"I had goodness knows how many doctors and nurses rushing in, next I knew somebody was trying to take earrings out of my ears, my rings off my fingers. I was, um, wheeled down to theatre ... I'd obviously had this pethidine and then it come to the doors just before going into the theatre and somebody came to me with a clipboard, with a form and just said sign this." (Participant 7, emergency)

These eight participants felt their signature on the consent form was nothing more than the fulfilment of a bureaucratic requirement of little significance in demonstrating their true understanding or agreement. In six cases of surgery seen as imposition or imposed rescue, participants argued that signed consent does not equate to an expressed preference or "real" consent. In these cases, women did not appear to accept the legitimacy of the medical decision, even where the rationale for that decision was presented in terms of safety or survival of a third party in the form of a baby.

"I feel as if I was told to have a caesarean. I didn't consent to a caesarean you know. I didn't say yes I want a caesarean that's fine you know. I've not really consented although I've signed this form, I've not consented you know to a caesarean." (Participant 23, emergency)

There was evidence in the accounts of three women (all emergencies) who had serious reservations about surgery that they did not exercise their option to refuse to sign the consent form. One woman, for example, was extremely resistant to having a caesarean section and identified the request to sign the consent form as her chance to refuse, but found it impossible to do this.

"I could've thrown the pen. I could've said ... I could've screamed, I could've done. I could've said no way, but I signed it." (Participant 17, emergency)
Only one participant chose to activate her "right of refusal" when confronted with a consent form. This participant was unusual as she had "insider" status as a health professional. She refused (at least initially, although she later changed her position) to sign a form consenting to removal of an ovarian cyst during pregnancy, because of the risks to her fetus.

Participants who signed the form despite having reservations reported that they were unwilling or unable to question professionals, primarily because they felt disempowered by the forms of etiquette that govern the surgeon-patient relationship, which they felt cast patients in the role of non-experts and doctors in the role of unchallengeable experts. Participants also reported that they lacked the resources, primarily information, to resist decisions being made on their behalf. Participants were acutely aware that their role in terms of the consent process was pre-scripted: it was virtually impossible to challenge the expectation that they must sign the form.

“... I just felt like a naughty schoolgirl really and it's like the teacher coming round and saying right this is what is going to have to happen to you and that's that really, sign it ... Even in that situation, I think I probably could of said no, but I didn't have nothing to justify why I was saying no, because they hadn't given me enough information for me to say no." (Participant 15 , emergency)

\section{DISCUSSION}

Consent has evolved as a key process in signalling the outcomes of decision making and providing a means of promoting more partnership-based forms of professionalpatient relationships. In contrast to previous studies which have seen the defining outcome of consent as measures of fact retention or recall of information by patients, ${ }^{9} 102021$ this study addresses patients' perceptions of the process as an index of its quality. We found that provision of information was only one of many factors contributing to patients' experience of the consent process. Our study also identified that a process that does not recognise the diversity of types of decision and circumstances under which decisions are made will be inadequate. In particular, despite some overlap, the experiences and views of women undergoing emergency and planned procedures are broadly distinct and are likely to require different processes.

This study offers a qualitative analysis of the accounts of 25 women who had consented to a range of surgical procedures under a range of conditions. It is possible, but unlikely, that the experience of these women is unique. They were drawn from diverse backgrounds and were managed by different doctors. The hospital as a whole has a clear and widely disseminated consent policy based on national guidelines. The patient panel's involvement provided a safeguard against biomedical "framing" of the research. However, some care is clearly required in interpreting accounts of past events even if they are recent. Narratives such as those reported here allow experiences to be understandable within a lay framework rather than a medical one, but they are sometimes constructed in ways which allow them to be read as demonstrations of personal competence. ${ }^{22}$ Narrative devices, including "atrocity stories" of medical incompetence or inhumanity, have been identified in the sociological literature as common features of such accounts, with the well known characteristics of describing encounters with medicine that involve conflict and disagreement about doctors' behaviour as judged against lay standards. ${ }^{23}$ The arrangement of events to fit a narrative mode or "plot" may mean that participants' accounts suggest more coherence than was apparent at the time. This is a feature of narrative based research ${ }^{24}$ that might possibly be addressed by obtaining contemporaneous accounts, although these might be prone to other types of 
biases and be practically difficult to access. It is therefore important that the accounts analysed in this paper are seen as reflections and constructions of what happened from the perspective of patients, rather than providing direct access to the events. Nonetheless, the accounts do offer important insights into how women who have consented to surgery represent their experiences.

Participants' accounts in this study made no reference to ethics. All participants had signed the consent form, including some (mostly women who had undergone emergency operations) who signed despite serious doubts and reservations. This study included women who had experienced a range of operations, but the key difference between those who were unhappy with the consent process and those who were not lay not in the type of operation (including whether it was emergency or elective, and whether there was a baby involved or not) but in the extent to which they recognised the operation as a legitimate intervention and the extent to which they wanted it. We identified four distinct orientations to surgery among the study participants, which strongly influenced orientations towards consent and to a large extent reflected the extent to which women felt involved in decision making. While some-particularly those undergoing planned procedures or emergency procedures that they wanted-felt able to participate in decision making and either desired or welcomed surgery, others were more passive. This latter group saw surgery as "happening to them", either with their collusion or, more alarmingly, in the face of deeply held (though unvoiced) scepticism or even hostility. Women who had undergone emergency procedures appeared much more likely to be unhappy, possibly because of their much more limited involvement in decision making and the conditions under which the decision was made.

Regardless of orientations toward surgery, there was a strong tendency to view consent as ritualistic, bureaucratic, and embedded within a legal rather than an ethical framework. The significance of this varied depending on whether women wanted surgery or not. Many of those who wanted surgery saw the process of signing the consent form as redundant, yet it failed to empower those with reservations or concerns. Some of these concerns arose in a context where the safety of either the woman or a baby appeared to be at stake, but the consent process, which should have secured the understanding and agreement of the participants, appears to have failed. Women in this category did not recognise the legitimacy either of the medical case or of the seizure of control by doctors claiming to be acting in their interests or those of their baby. The issues that affect women whose baby's life or safety is at stake in decision making about surgery are clearly of enormous interest because of the dyadic effects. While we were unable to explore these issues in detail in the current paper, it will be an important focus of future research in the area of consent.

This study showed that, while consent forms are seen as offering some advantages to patients, they were not recognised by patients as operating solely or even primarily in their own interests. Most see consent as part of a ritual embedded in the ceremony of surgery, and as the inevitable outcome of a process initiated by professionals. It is clear from the accounts offered by participants that the meanings of consent are crucially dependent on the meanings given to surgery. Although the consent form is uniform across all clinical situations for all adults with capacity, the experience of consent is not a uniform process with the same outcomes for all people. Despite the highly contingent context of decision making about surgery, participants recognise that their own role in the consenting ritual has already been scripted and that they are all required to act it out in the same way. ${ }^{25}$ If they do want surgery, this is relatively
Key messages

- Current debates on consent have put it at the centre of the professional-patient relationship and have emphasised the importance of disclosure of information.

- The current standardised consent process falls short of enabling partnership and promoting autonomy.

- People who give consent often view it as bureaucratic, legal or ritualistic, and not primarily as serving their interests.

- There is some evidence that the consent process can operate oppressively in situations where people would prefer to resist intervention.

- There is a need for consent processes to recognise the different circumstances under which consent may be given.

unproblematic. However, if patients are ambivalent or resistant to surgery, or in an extreme physical or psychological state, the consenting process becomes a potentially oppressive one where consent is obtained so that the appearance of consent can be maintained and the ritual proceeds smoothly. The ways in which the routines of the hospital are orchestrated means that patients feel they are the subjects of the process rather than autonomous agents. Patients who do not want surgery identify the role of the consent form as primarily legitimising the decisions and actions of doctors. Similar findings have been found in research settings, ${ }^{26}$ but the difficulties in everyday practice are only now beginning to be recognised ${ }^{27}{ }^{28}$ These are disturbing findings, particularly in the light of recent UK policy initiatives on the importance of recognising the expertise of patients and promoting involvement in decision making. ${ }^{29}$

Ironically, given the status afforded to consent in bioethical debates as the safeguard of patients' autonomy, the current process does not appear to reflect patients' own priorities. Participants' perceptions of consent as mainly providing legal cover for healthcare providers are likely to impair trust and confidence. Such findings call into question the validityboth legal and ethical-of consent, especially under emergency situations. It also challenges the utility of the approach to consent featuring lengthy documents. These findings also appear to provide some empirical support for the recent questioning of the utility of consent as an antidote for medical paternalism and as an expression of patients' right to self-determination. These arguments place consent within a dominant-subordinate relationship that is at odds with liberty and autonomy. ${ }^{1}$ Of particular concern are our findings in relation to emergency procedures, where a large proportion of the more serious problems in relation to consent appeared to arise. Little distinction is made in current literature or in published guidance between the requirements for consent in emergency and elective surgery, other than where the patient is unconscious.

The ethical requirement to counter paternalism will remain difficult to achieve if issues surrounding consent continue to be debated between professionals-whether in medical, bioethical or legal circles-without due effort to access patients' own views and values and to appreciate the circumstances under which consent is sought. There is a need for an approach that is more personal and engaging, and more rooted in the preferences of patients themselves. ${ }^{30}{ }^{31}$ Professionals need to be highly sensitised to the ways in which people can feel disempowered in clinical practice, particularly in emergency situations, and to encourage 
people to voice their concerns and questions rather than taking silence and the signature on the consent form as evidence of positive endorsement of clinical decisions. Future research is needed to ascertain the extent by which the findings in this study are applicable to men and women undergoing different types of surgery, and to quantitatively examine the relative importance of the parameters identified in this study in elective compared with emergency surgery.

\section{ACKNOWLEDGEMENTS}

The authors thank the members of the patient panel who helped with this project for their valuable and insightful input, Trent NHS Executive Office for funding the study, and Jennifer Kurinczuk for helpful comments on drafts.

\section{Authors' affiliations}

M Habiba, C Jackson, A Akkad, S Kenyon, Reproductive Sciences Section, University of Leicester, Leicester LE2 7LX, UK

M Dixon-Woods, Department of Health Sciences, University of Leicester, Leicester LE1 6TP, UK

Financial support: Trent NHS Executive Office

\section{REFERENCES}

1 Habiba MA. Examining consent within the doctor-patient relationship. J Med Ethics 2000;26:183-7.

2 O'Neill O. Informed consent and genetic information. Studies in History and Philosophy of Science Part C: Studies in History and Philosophy of Biological and Biomedical Sciences 2001;32:689-704.

3 Department of Health. Reference guide to consent for examination or treatment. London: Department of Health, 2001 (available at www.doh.gov.uk/consent).

4 General Medical Council. Seeking patients' consent: the ethical considerations. London, General Medical Council, 1998 (available at www.gmc-uk.org).

5 Coulter A. After Bristol: putting patients at the centre. BMJ 2002;324:648-51

6 Beauchamp TL, Childress JF. The principle of respect for autonomy. In: Principles of biomedical ethics. 3rd ed. New York: Oxford University Press, 1989:67-119.

7 Kennedy I, Grubb A. Medical law, 3rd ed. London: Butterworths, 2000:574-83

8 Gillon R. Medical treatment, medical research and informed consent. J Med Ethics 1989;15:3-5.
9 Chan Y, Irish JC, Wood SJ, et al. Patient education and informed consent in head and neck surgery. Arch Otolaryngol Head Neck Surg 2002; 128:1269-74

10 Chan ECY, Sulmasy DP. What should men know about prostate-specific antigen screening before giving informed consent? Am J Med 1998; 105:266-74.

11 Dixon-Woods M. Writing wrongs? An analysis of published discourses about the use of patient information leaflets. Soc Sci Med 2001;52:1417-32.

12 Salgo v Leland Stanford Jr University Board of Trustees [1957] 317 P2d 170 (Calif).

13 Sidaway v Board of Governors of the Bethlem Royal Hospital [1985] AC 871, [1985] 1 A11 ER 643 (HL).

14 Rogers v Whitaker [1992] 109 ALR 625 at 631, [1993] 4 Med LR 79 at 82 (High Court of Australia).

15 Kelly SE. Bioethics and rural health: theorizing time, space, and subjects. Soc Sci Med 2003;56:2277-88.

16 Chambers T. The fiction of bioethics: cases as literary text. New York: Routledge, 1999

17 Patton MQ. Qualitative evaluation and research methods, 2nd ed. Newbury Park, CA: Sage, 1990.

18 Glaser BG, Strauss AL. The discovery of grounded theory: strategies for qualitative research. Chicago: Aldine, 1967.

19 Gahan C, Hannibal M. Doing qualitative analysis with QSR NUD.IST 4. London: Sage, 1998.

20 Bottrell MM, Alpert H, Fischbach RL, et al. Hospital informed consent for procedure forms: facilitating quality patient-physician interaction. Arch Surg 2000;135:26-33.

21 Vohra HA, Ledsham J, Vohra H, et al. Issues concerning consent in patients undergoing cardiac surgery-the need for patient-directed improvements: a UK perspective. Cardiovasc Surg 2003;11:64-9.

22 Dixon-Woods M, Findlay M, Young B, et al. Parents' accounts of obtaining a diagnosis of childhood cancer. Lancet 2001;357:670-4.

23 Baruch G. Moral tales: parents' stories of encounters with the health professions. Sociol Health Illness 1981;3:275-95.

24 Hyden L. Illness and narrative. Sociol Health Illness 1997;1:48-69.

25 Strong P. Minor courtesies and macro structures. In: Drew P, Wootton A, eds Erving Goffman: exploring the interaction order. Cambridge: Polity Press, 1988.

26 Ågård A, Hermerén G, Herlitz J. Patients' experiences of intervention trials on the treatment of myocardial infarction: is it time to adjust the informed consent procedure to the patient's capacity? Heart 2001;86:632-7.

27 Chassin MR, Becher EC. The wrong patient. Ann Intern Med 2002;136:826-33.

28 Meredith P. Patient participation in decision making and consent to treatment: the case of general surgery. Sociol Health Illness 1993;15:315-36.

29 http://www.doh.gov.uk/involvingpatients/index.htm (accessed 2 June 2003).

30 Veatch RM. The concept of 'medical indications'. In:The patient-physician relation:the patient as partner. Part 2 (Medical Ethics Series). Bloomington: Indiana University Press, 1991:54-62.

31 Veatch RM. Abandoning informed consent. Hastings Cent Rep 1995;25:5-12

Call for papers

10th European Forum on Quality Improvement in Health Care

13-15 April 2005, ExCel, Docklands, London

For further information on how to submit your paper please go to:

http://www.quality.bmipg.com 